
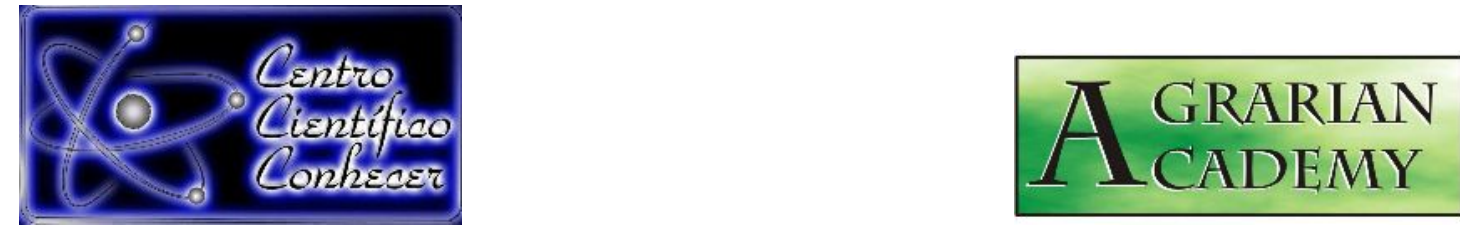

\title{
INFLUÊNCIA DO LODO DE ESGOTO DA ESTACÃO DE TRATAMENTO DE EFLUENTES NOS ATRIBUTOS MICROBIOLÓGICOS DO SOLO
}

\footnotetext{
Jéssica Andrade Cypriano ${ }^{1}$; Joseane Oliveira da Silva ${ }^{2}$; Victor Lima Souza ${ }^{3}$; Sara Moreno Lacerda Pereira ${ }^{4}$; Felizardo Adenilson Rocha ${ }^{5}$

${ }^{1}$ Graduada em Engenharia Ambiental do Instituto Federal de Educação Ciência e Tecnologia da Bahia (e-mail: cypriano108@gmail.com) Vitória da Conquista-Brasil

${ }^{2}$ Professora Doutora do Departamento de Engenharia Ambiental do Instituto

Federal de Educação Ciência e Tecnologia da Bahia

${ }^{3}$ Graduando em Engenharia Ambiental do Instituto Federal de Educação Ciência e Tecnologia da Bahia

${ }^{4}$ Graduanda em Engenharia Ambiental do Instituto Federal de Educação Ciência e Tecnologia da Bahia

${ }^{5}$ Professor Doutor do Departamento de Engenharia Ambiental do Instituto Federal de Educação Ciência e Tecnologia da Bahia
}

Recebido em: 20/11/2019 - Aprovado em: 15/12/2019 - Publicado em: 30/12/2019 DOI: 10.18677/Agrarian_Academy_2019b4

\begin{abstract}
RESUMO
O lodo oriundo das Estações de Tratamento de Efluentes (ETE) possui um grande potencial no que diz respeito à nutrição e à alta quantidade de material orgânico, o que possibilita a utilização como condicionante do solo e em culturas agricultáveis. Contudo, o lodo pode estar sujeito a agentes poluentes, sendo necessário um manejo de controle adequado. Como os microrganismos exercem uma atuação na transformação e decomposição da matéria orgânica e têm uma boa resposta as alterações ambientais, é de grande relevância o estudo dos atributos biológicos do solo pelo seu uso. O trabalho teve como objetivo avaliar a influência de diferentes doses do lodo de esgoto da ETE nos atributos microbiológicos do solo. O experimento foi conduzido no laboratório de Solos do IFBA, campus Vitória da Conquista - BA e na Universidade Estadual do Sudoeste da Bahia, campus Vitória da Conquista- BA. O solo utilizado foi o Latossolo Vermelho Amarelo distrófico. $\mathrm{Na}$ análise, foi utilizado o Delineamento Inteiramente Casualizado (DIC), com cinco doses do lodo do município de Vitória da Conquista - BA, subdividida em cinco proporções: $0 ; 4 ; 8 ; 16$ e $32 \mathrm{Mg} / \mathrm{ha}$, com três repetições. Foram determinados três indicadores biológicos do solo: Respiração Basal do Solo (RBS), o carbono da biomassa microbiana (CBM) e o quociente metabólico $\left(q \mathrm{CO}_{2)}\right.$. De acordo com os resultados, pode-se observar que o tratamento $32 \mathrm{Mg} / \mathrm{ha}$ apresentou maior incremento na RBS, CBM e no $9 \mathrm{CO}_{2}$.
\end{abstract}

PALAVRAS-CHAVE: efluente; indicadores biológicos do solo; microrganismos. 


\title{
INFLUENCE OF SEWAGE SLUDGE FROM EFFLUENT TREATMENT STATION ON SOIL MICROBIOLOGICAL ATTRIBUTES
}

\begin{abstract}
Sludge from Effluent Treatment Stations (ETS) has great potential for nutrition and high amount of organic material, which makes it possible to use as a conditioner of the soil and in agricultural crops. However, the sludge may be subject to polluting agents and appropriate control management is required. As microorganisms play a role in the transformation and decomposition of organic matter and have a good response to environmental changes, it is very important to study the biological attributes of the soil through its use. The aim of this work was to evaluate the influence of different doses of sewage sludge from ETE on the soil microbiological attributes. The experiment was conducted at the IFBA Soil Laboratory, Vitória da Conquista - BA campus and at the Southwest Bahia State University, Vitória da Conquista - BA campus. The soil used was the dystrophic Red Yellow Oxisol. In the assay, a Completely Randomized Design (CRD) was used, with five doses of sludge from Vitória da Conquista - BA, subdivided into five proportions: $0 ; 4 ; 8 ; 16$ and 32 $\mathrm{Mg} / \mathrm{ha}$ with three replications. Three soil biological indicators were determined: Basal Soil Respiration (BSR), the microbial biomass carbon (MBC) and the metabolic quotient (qCO2). According to the results, it can be observed that the $32 \mathrm{Mg} / \mathrm{ha}$ treatment showed the highest increase in RBS, MBC and qCO2.
\end{abstract}

KEYWORDS: effluent; microorganisms; soil biological indicators.

\section{INTRODUÇÃO}

O solo representa a parte superficial da crosta da terra, sendo um recurso fundamental na composição do ecossistema. O conhecimento das características do solo é obtido por meio do uso de indicadores. Os indicadores são atributos que fazem a medição ou fornecem a condição do biossistema. Os parâmetros qualitativos são classificados como físicos, químicos e biológicos (BUENO et al., 2018).

O indicador que melhor se apresenta na composição da qualidade do solo é a biomassa. Pelo potencial de alteração e sensibilidade às modificações no manuseio em solo e às transformações na biologia e na química de materiais tendem a modificar a biomassa microbiana e influenciar na aptidão do uso de Carbono, o que provoca a sua formação em diferentes fontes de material orgânico (BONINI et. al., 2015).

Os microrganismos participam de diferentes ações que modificam o biossistema, relacionando-se com o dinamismo da Matéria Orgânica do Solo (MOS)., no ciclo de nutrientes, fertilização do solo e modificações no Carbono (C). A sua capacidade tende a reagir de forma vertiginosa aos atributos dos microbianos atuantes no solo, o que não é perceptível nos indicativos físicos ou químicos. Isso pode refletir, em determinados casos, de forma positiva: melhorando a qualidade e, de forma negativa, com sua deterioração (SILVA et al., 2017).

O uso de técnicas para mensurar a atuação de microrganismos pode ser obtida por análises bioquímicas do solo. A respiração microbiana do solo é um dos métodos mais comuns, obtido pela absorção do Oxigênio $\left(\mathrm{O}_{2}\right)$ como também pela liberação de Dióxido de Carbono $\left(\mathrm{CO}_{2}\right)$ no meio, por ações de mudanças de gases oriundos do metabolismo de organismos, tendo relação positiva com a MOS e com a biomassa (SANTOS; BATISTA, 2015).

AGRARIAN ACADEMY, Centro Científico Conhecer - Goiânia, v.6, n.12; p. 37 2019 
Segundo Anderson e Domsch (1993), o arranjo das medidas de respiração do solo em conjunto com a biomassa microbiana fornece o quociente metabólico $\left(q \mathrm{CO}_{2}\right)$, que é a relação da quantidade de $\mathrm{CO}_{2}$ liberada pela unidade de Carbono da biomassa e pela unidade de tempo, um vez que é usada para analisar os efeitos ambientais e antropogênicos da biomassa e da atuação dos microrganismos.

O lodo de esgoto é um resíduo rico em material orgânico, semissólido, com diferentes índices de compostos inorgânicos, originado pela ação do tratamento de águas residuais nas ETE's, que comumente são destinados a aterros sanitários (BERTICELLI et al., 2016). Com o tratamento o lodo se caracteriza como um potencial de compostos orgânicos para possível utilização no meio, em relação ao melhoramento no solo, atua como um condicionador (PEREIRA; GARCIA, 2017). O lodo não utilizado, quando acumulado em grandes quantidades nas Estações de Tratamento, tornam-se agentes impactantes para o meio ambiente.

Cardoso e Fortes Neto (2000) analisaram a utilização do lodo proveniente de esgoto em um solo e evidenciaram que a RBS e o $q \mathrm{CO}_{2}$ obtiveram um aumento, sendo que a biomassa do local se manteve sem alterações. A inserção de lodos no solo, provindo de residências ou de setores industriais, pode alterar o desempenho e a forma estrutural do ecossistema, tendo em vista que a população de microrganismos é um dos elementos com mais sensibilidade para determinar os atributos do solo (NOVAK et al., 2017). A atividade microbiana pode ser estimulada com o uso desses materiais, proveniente do elevado índice de $\mathrm{C}$ e da nutrição disponível, de maneira que proporciona a inibição de metais pesados e outros agentes poluidores.

Assim, a comunidade microbiana tem uma interdependência quanto a sua reação, visto pela quantidade e qualidade dos resíduos no solo (MOREIRA et al., 2019). Diante do exposto, o trabalho teve como objetivo geral avaliar a influência de diferentes doses do lodo de esgoto da estação de tratamento de efluente nos atributos microbiológicos do solo.

\section{MATERIAL E MÉTODOS}

\section{Amostragem}

O experimento foi conduzido no Laboratório de Solos do Instituto Federal de Educação, Ciência e Tecnologia da Bahia (IFBA) e no Laboratório de Microbiologia da Universidade Estadual do Sudoeste da Bahia, campus Vitória da Conquista, BA. O solo utilizado foi o Latossolo Vermelho Amarelo distrófico, típico, textura franco argilo arenosa, relevo plano, coletado na camada de 0 a 0,2 metros. Após a coleta, as amostras de solos foram destorroadas e peneiradas em malha de $8 \mathrm{~mm}$ para caracterização química, conforme o quadro 1.

QUADRO 1- Resultado da análise química do solo utilizado no experimento antes da implantação.

\section{Profundidade De 0-20 cm}

LVA

\begin{tabular}{cc}
\hline $\mathbf{P H}_{\mathrm{H} 2 \mathrm{O}}$ & $5,2 \mathrm{mg} / \mathrm{dm}^{3}$ \\
\hline $\mathbf{P}$ & $1 \mathrm{cmol} / \mathrm{dm}^{3}$ \\
$\mathbf{M g}$ & $0,50 \mathrm{cmol} / \mathrm{dm}^{3}$ \\
\hline
\end{tabular}




\begin{tabular}{cc}
$\mathbf{K}_{\mathbf{I}}$ & $0,02 \mathrm{cmol}_{\mathrm{c}} / \mathrm{dm}^{3}$ \\
\hline $\mathbf{C a}$ & $0,20 \mathrm{cmol}_{\mathrm{d}} / \mathrm{dm}^{3}$ \\
\hline $\mathbf{A}$ & $0,40 \mathrm{cmol}_{\mathrm{d}} / \mathrm{dm}^{3}$ \\
\hline $\mathbf{H}$ & $3,40 \mathrm{cmol}_{\mathrm{c}} / \mathrm{dm}^{3}$ \\
\hline SB & $0,70 \mathrm{cmol}_{\mathrm{c}} / \mathrm{dm}^{3}$ \\
\hline $\mathbf{t}$ & $1,10 \mathrm{cmol}_{\mathrm{d}} / \mathrm{dm}^{3}$ \\
\hline $\mathbf{T}$ & $4,50 \mathrm{cmol} / \mathrm{dm}$ \\
\hline $\mathbf{V}$ & $16 \%$ \\
\hline $\mathbf{M}$ & $36 \%$ \\
\hline MO & $12 \mathrm{mg} / \mathrm{dm}^{3}$ \\
\hline
\end{tabular}

Fonte: UESB: Laboratório de solos.

Antes do início do experimento, o lodo foi amostrado para determinação das características químicas $\left(\mathrm{pH}, \mathrm{P}, \mathrm{K}^{+}, \mathrm{Na}^{+}, \mathrm{Ca}^{2+}, \mathrm{Mg}^{2+}\right.$, matéria orgânica - $\mathrm{MO}, \mathrm{N}-$ total, $\mathrm{Zn}, \mathrm{Fe}, \mathrm{Mn}, \mathrm{Cu}, \mathrm{B}, \mathrm{S})$, conforme metodologias propostas pela EMBRAPA (1997), de acordo com a TABELA 1.

TABELA 1 Resultado da análise química do lodo da ETE utilizado no experimento.

\begin{tabular}{cc} 
Substrato & Lodo \\
& ETE \\
$\mathbf{p H}$ & $6,1 \%$ \\
\hline $\mathbf{C a}$ & $2,00 \%$ \\
\hline $\mathbf{M g}$ & $0,30 \%$ \\
\hline $\mathbf{K}_{\mathbf{2}} \mathbf{O}_{\text {sol }}$ & $0,08 \%$ \\
\hline $\mathbf{K}_{\mathbf{2}} \mathbf{O}_{\text {Total }}$ & $0,10 \%$ \\
\hline $\mathbf{N}$ & $2,58 \%$ \\
\hline $\mathbf{P}_{\mathbf{2}} \mathbf{O}_{\text {Ttotal }}$ & $0,80 \%$ \\
\hline $\mathbf{C}$ & $31,87 \mathrm{mg} / \mathrm{dm}^{3}$ \\
\hline $\mathbf{M} . \mathbf{O}$ & $58,96 \mathrm{mg} / \mathrm{dm}^{3}$ \\
\hline $\mathbf{F e}$ & $33269 \mathrm{mg} / \mathrm{dm}^{3}$ \\
\hline $\mathbf{Z n}$ & $1617 \mathrm{mg} / \mathrm{dm}^{3}$ \\
\hline $\mathbf{C u}$ & $266 \mathrm{mg} / \mathrm{dm}^{3}$ \\
\hline $\mathbf{M n}$ & $164 \mathrm{mg} / \mathrm{dm}^{3}$ \\
\hline
\end{tabular}

Fonte: UESB: Laboratório de solos.

O lodo foi colocado em um recipiente plástico para a secagem ao ar e posteriormente triturado e utilizado como base seca.

\section{Determinação da Respiração Basal do Solo (RBS)}

Para a respiração basal do solo, foi seguida a metodologia proposta por Jenkinson e Powlson (1976), os quais foram pesados $50 \mathrm{~g}$ de solo para cada tratamento (Figura 1), sendo posteriormente misturados com a quantidade de lodo respectiva para cada tratamento e então, umedecidos de acordo com a determinação da umidade relativa frente à capacidade de campo do solo (Figura 2). 


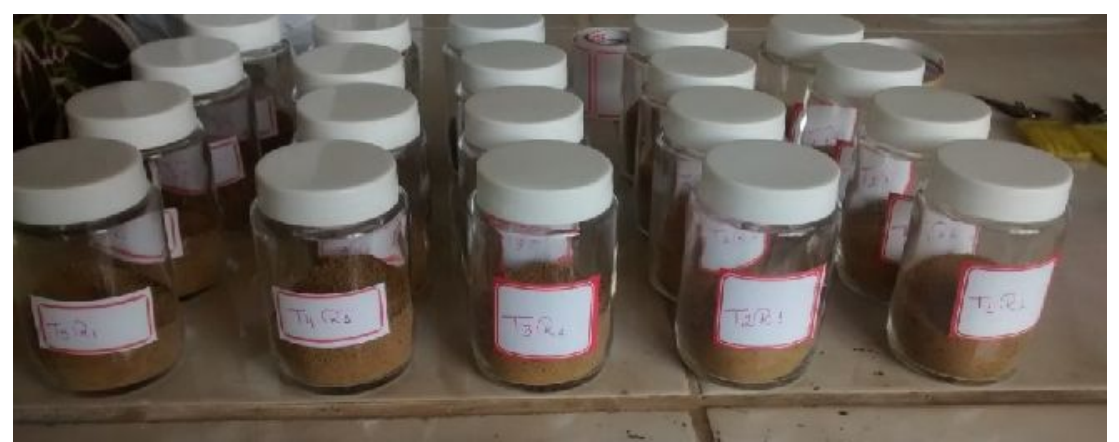

FIGURA 1 - Pesagem do solo nos SnapCaps, com respectivas identificações para cada tratamento.

Fonte: autores.

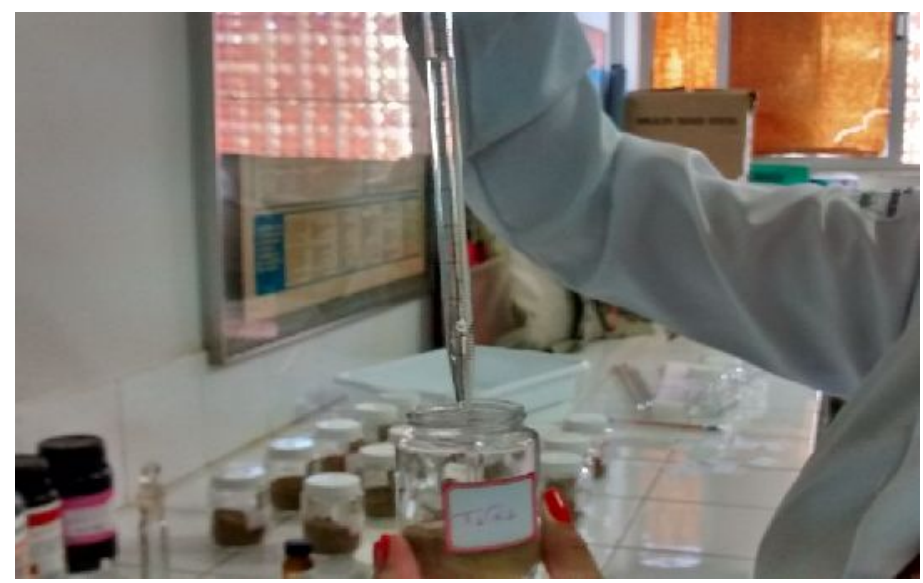

FIGURA 2 - Umedecimento do solo frente a capacidade de campo.

Fonte: autores

Deu-se segmento à primeira parte do procedimento com a incubação do solo, durante sete dias, juntamente com $10 \mathrm{~mL}$ da solução de hidróxido de sódio $(\mathrm{NaOH})$ $1 \mathrm{M}$, anteriormente preparada. Salienta-se que foram incubados recipientes com apenas $\mathrm{NaOH}$, para a solução controle (branco). A incubação se deu em recipientes de vidro de $2 \mathrm{~L}$, devidamente fechados e armazenados em ambiente escuro. Após esse período, retirou-se o recipiente com $10 \mathrm{~mL}$ de $\mathrm{NaOH}$ e adicionou-se $2 \mathrm{~mL}$ da solução de Cloreto de Bário $\left(\mathrm{BaCl}_{2}\right)$, anteriormente preparada, para completa precipitação do carbono, conforme a figura 3.

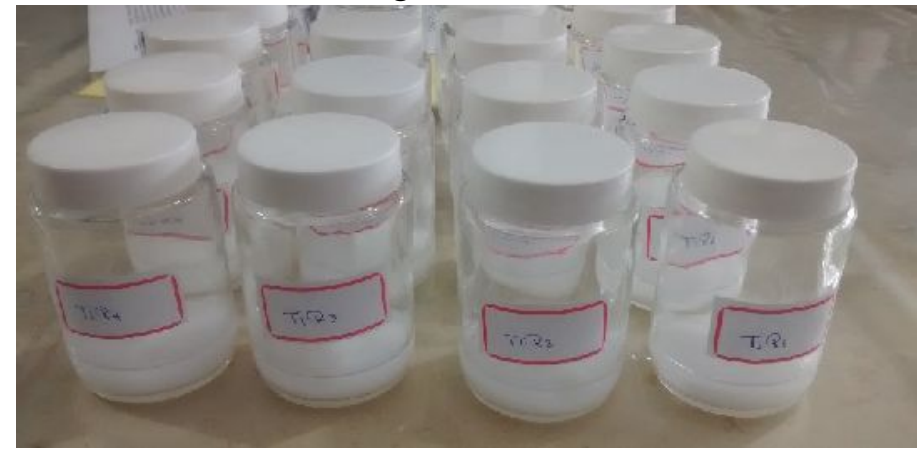

FIGURA 3 - $10 \mathrm{~mL}$ da solução de $\mathrm{NaOH}$, após a incubação, com adição de $2 \mathrm{~mL}$ de $\mathrm{BaCl}_{2}$.

Fonte: autores 
Após a adição de $\mathrm{BaCl}_{2}$, o recipiente com a solução precipitada foi rapidamente fechado, para posterior titulação com solução de ácido clorídrico $0,5 \mathrm{M}$. Antes da titulação adicionou-se, em cada repetição para cada tratamento, 2 gotas de fenolftaleína $2 \%$, anteriormente preparada. Ao final da titulação, a coloração da solução passou de rosa para branco leitoso.

\section{Determinação do Carbono da Biomassa Microbiana do Solo (BMS)}

O carbono da biomassa microbiana seguiu a metodologia proposta por Vance et al., (1987). Inicialmente, foram pesados $20 \mathrm{~g}$ do mesmo solo utilizado na determinação da RBS, com a respectiva adição de lodo para cada tratamento e umedecimento de acordo com a umidade relativa frente à capacidade de campo do solo. Foi utilizado um total de 40 amostras, sendo 20 fumigadas e 20 não-fumigadas.

As amostras fumigadas foram colocadas em um dessecador, juntamente com dois SnapCaps: um contendo clorofórmio e o outro contendo água deionizada. O dessecador foi acoplado a uma bomba de vácuo, ligada durante 15 minutos e, posteriormente, o recipiente foi armazenado em ambiente completamente escuro por 18 horas. Após esse período, as amostras foram retiradas do dessecador e procedeu-se com a etapa de extração. As amostras não-fumigadas foram diretamente submetidas à essa etapa.

Uma solução de Sulfato de Potássio $\left(\mathrm{K}_{2} \mathrm{SO}_{4}\right)$ foi preparada para que $50 \mathrm{~mL}$ fossem adicionados em cada frasco. Depois da adição, os fracos foram submetidos à agitação constante durante 15 minutos e, posteriormente, à decantação por mais 15 minutos. Dando continuidade ao procedimento, as amostras já decantadas foram filtradas com auxílio de funil e de papel filtro, conforme a figura 4, e posteriormente armazenadas em câmara fria. De acordo com a metodologia de De-Polli e Guerra (1997), os extratos poderiam ficar armazenados em geladeira a $4^{\circ} \mathrm{C}$ por até 10 dias.

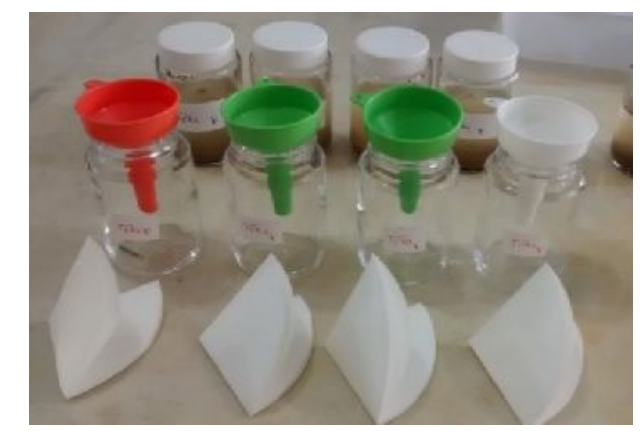

FIGURA 4 - Disposição dos funis, papéis-filtros e recipientes limpos para procedimento de filtração.

Fonte: autores

Para a determinação do carbono da biomassa, elaborou-se a Solução Trabalho (ST) com a adição de outras soluções anteriormente preparadas, bem como a solução estoque de carbono, composta por ácido oxálico. Seguiu-se então com a elaboração das amostras que deveriam compor a curva padrão de carbono. As soluções foram lidas em espectrofotômetro para obtenção da absorbância e elaboração da curva padrão.

Finalmente, foram pipetados $2 \mathrm{~mL}$ do extrato, armazenado em geladeira, juntamente com $3 \mathrm{~mL}$ de água deionizada, 2,5 da ST e 2,5 de $\mathrm{H}_{2} \mathrm{SO}_{4}$. Essa solução foi deixada em repouso durante 18 horas para posterior leitura da absorbância em espectrofotômetro. A RBS foi calculada de acordo com a equação: 


$$
R B S=\frac{\frac{\left(\left(V_{b}-V_{a}\right) \cdot M \cdot 6 \cdot 1000\right)}{P_{s}}}{T}
$$

Em que, $V_{b}=$ volume de ácido clorídrico gasto na titulação do branco; $V_{a}=$ volume de ácido clorídrico gasto na titulação da amostra; $\mathrm{M}=$ molaridade do ácido clorídrico; $P_{s}=$ massa de solo seco; $\mathrm{T}=$ tempo de incubação, em horas. Posteriormente, para o cálculo do Carbono da Biomassa Microbiana (CBM), utilizouse a equação:

$$
C B M=F C \cdot k c^{-1}
$$

Em que, $\mathrm{FC}=$ diferença entre as amostras fumigadas e não-fumigadas e $\mathrm{kc}=$ 0,33 (fator de correção). $\mathrm{O} \mathrm{qCO}_{2}$ foi determinado pela relação entre a respiração do solo e a biomassa microbiana, podendo ser utilizado como sensível indicador de estresse quando a CBM é afetada. $\mathrm{O}$ cálculo $q \mathrm{CO}_{2}$ da respiração basal do solo é dado pela equação:

$\mathrm{qCO}_{2}\left(\mathrm{mgC}-\mathrm{CO}_{2} \cdot \mathrm{g}^{-1} \mathrm{BMS}-\mathrm{C} \cdot \mathrm{h}^{-1}=\frac{\mathrm{RBS}\left(\mathrm{mgC}-\mathrm{CO}_{2} \cdot \mathrm{kg}^{-1} \mathrm{solo} \cdot \mathrm{h}^{-1}\right.}{\mathrm{CBM}-\mathrm{C}\left(\mathrm{mgC} \cdot \mathrm{kg}^{-1} \mathrm{solo}\right) \cdot 10^{-3}}\right.$

Onde, $q \mathrm{CO}_{2}=$ Quociente metabólico do solo; RBS = Respiração basal do solo; $\mathrm{CBM}$ = Carbono da biomassa microbiana do solo. Ao final do experimento os dados foram submetidos a análise estatística, mais precisamente a análise de regressão através do programa estatístico SAEG 5.0 (GOMES, 1992).

\section{RESULTADOS E DISCUSSÃO}

Os valores encontrados para a Respiração Microbiana do Solo estão expostos na figura 5. Observou-se que quanto maior a dose de lodo aplicada, maior foi a RBS; um exemplo disso é que no tratamento de 32t/ha a RBS cresceu cerca de $400 \%$ em relação ao primeiro tratamento.

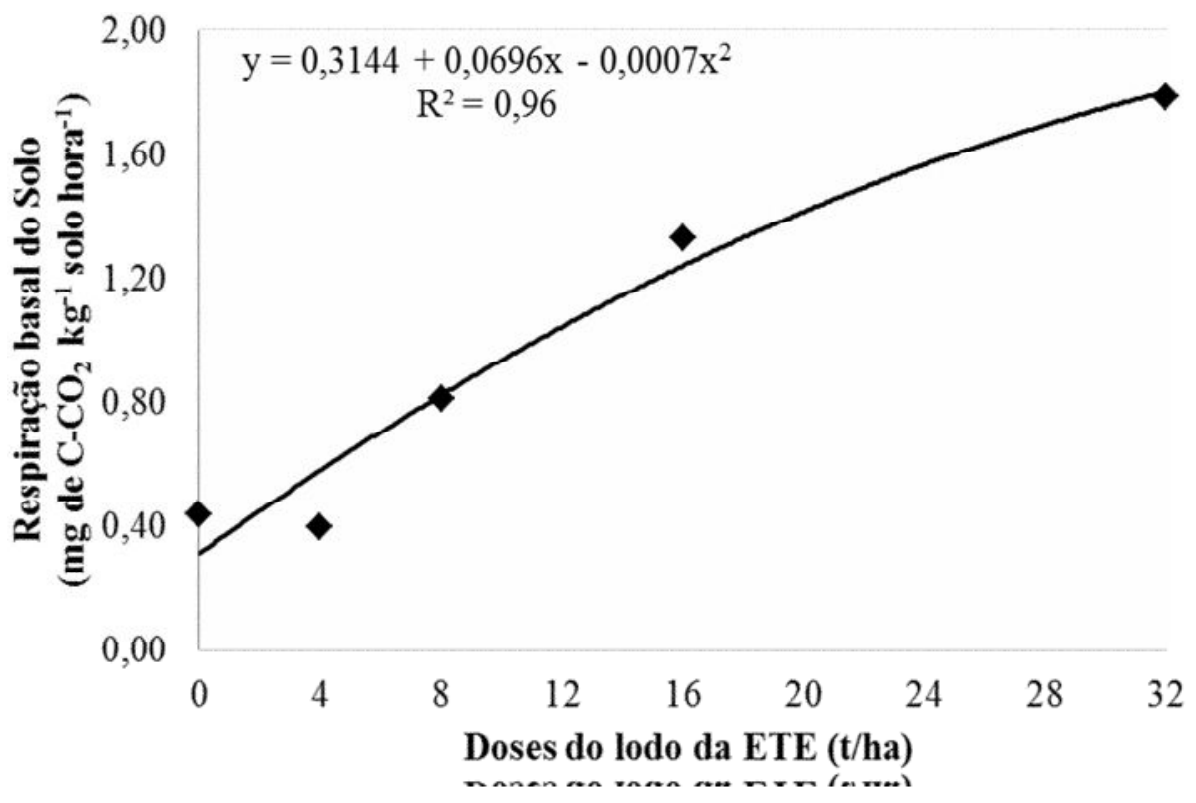

FIGURA 5 - RBS x Doses de lodo. 
Resultados semelhantes foram observados por Bohm et al., (2014) de forma que a taxa de respiração no tratamento com maior quantidade de lodo também foi a maior, sendo $54,83 \%$ maior do que a testemunha. Dessa forma, maiores dosagens de lodo implicaram em maiores taxas de RBS, sendo que, com o aumento das doses de lodo não foi observada inibição do processo respiratório, ou seja, os microrganismos responderam ao aumento das doses do lodo de esgoto da ETE.

De acordo com Andrade et al., (2016), o aumento da atividade microbiana com a aplicação de maiores doses do lodo está relacionado à maior disponibilidade de C orgânico para os microrganismos do solo, quando comparado ao tratamento sem aplicação do lodo. O carbono da biomassa microbiana pode ser observado na figura 6, com o mesmo propósito, isto é, a maior aplicação do lodo da ETE garantiu uma maior quantidade de carbono

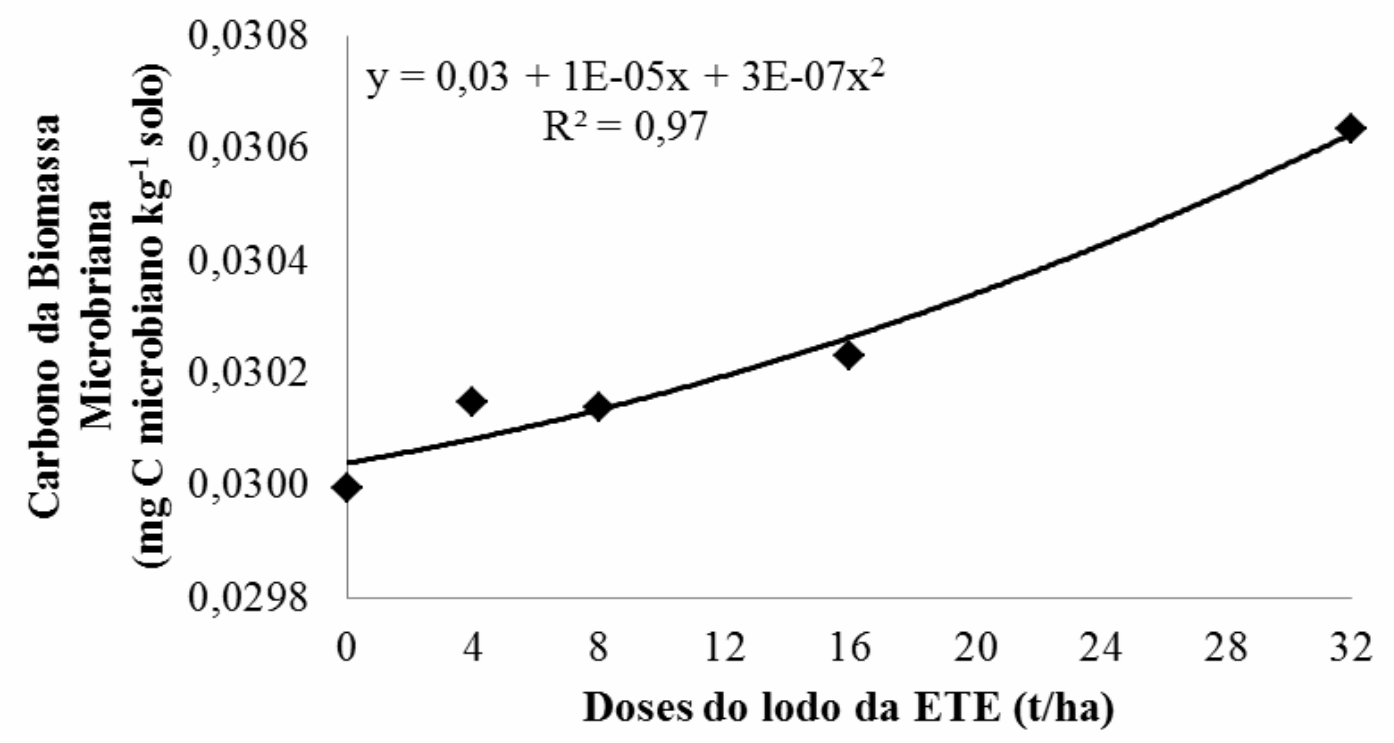

FIGURA 6 - CBM x Doses de lodo.

Este resultado significa que a massa microbiana total do solo estava em constante atividade, garantindo maior qualidade do solo, atuando em processos de decomposição natural e interagindo na dinâmica dos nutrientes (FERREIRA et al., 2017), constatando que o lodo testado pode ser aplicado ao solo, na dose $32 \mathrm{t}$ ha, com benefícios tanto a atividade e a biomassa microbiana do solo. Os valores encontrados (Figura 7) para o Quociente Metabólico, isto é, a razão entre a RBS e a BMS, foram superiores aos encontrados por Guimarães et al., (2017) e expressaram atividade microbiana elevada, com maior liberação de $C$ durante a respiração (BOHM et al., 2019). 


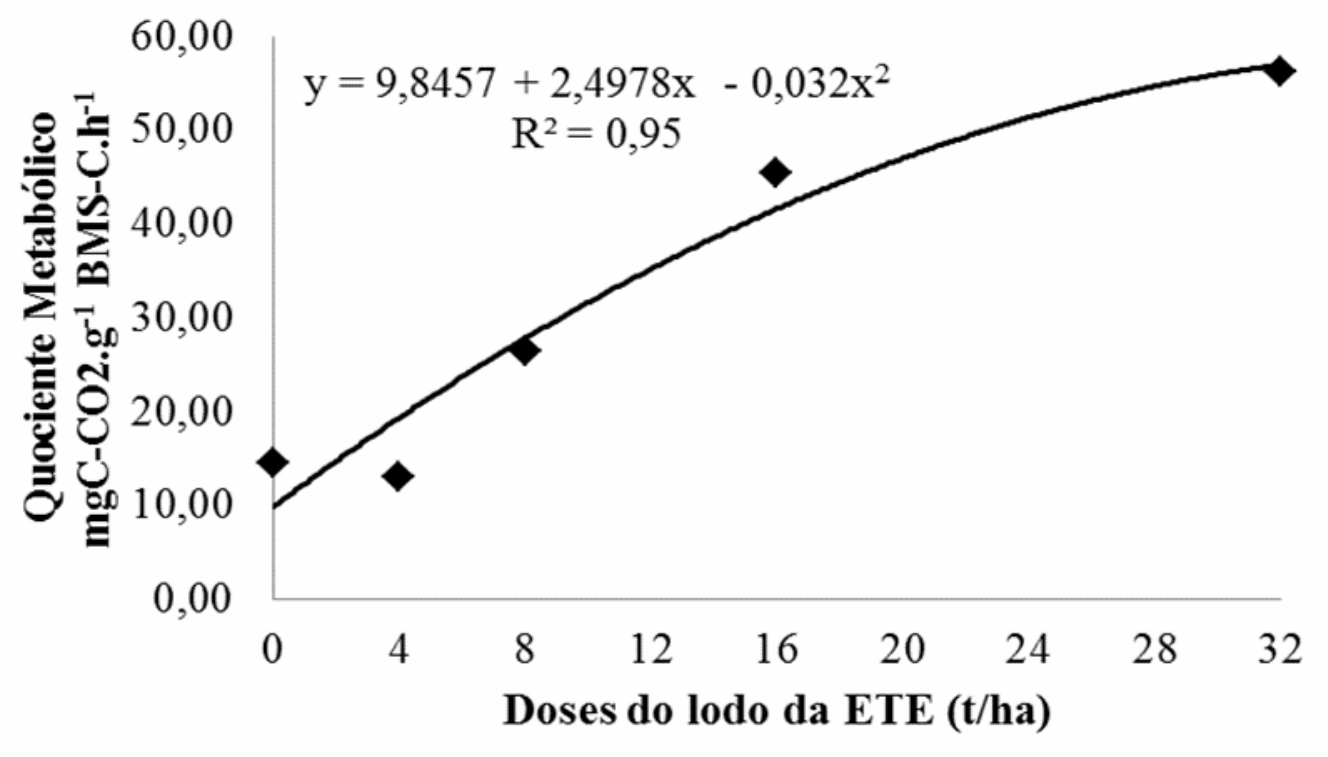

FIGURA $7-q \mathrm{CO}_{2} \times$ Doses de lodo.

O resultado se mostra positivo, visto que, à medida que a biomassa microbiana se torna mais elevada e, consequentemente mais eficiente, o processo de decomposição é mais rápido, devido à intensidade da atuação. Quocientes metabólicos elevados $\left(\mathrm{qCO}_{2}\right)$, como os observados neste estudo, indicam que pode estar ocorrendo maior gasto de energia para a manutenção da comunidade microbiana e, este resultado pode estar associado ao fato de que são um indicativo de populações microbianas em estágios iniciais de desenvolvimento e com maior proporção de microrganismos ativos em relação aos inativos (MELLONI et al., 2018).

\section{CONCLUSÕES}

Diante do exposto, observou-se que as maiores doses de lodo apresentam resultados mais satisfatórios, visto que o nível de matéria orgânica no solo é maior, e, consequentemente, a atividade microbiana, a quantidade de carbono da biomassa e o quociente metabólico também são maiores. Isso significa que a aplicação do lodo é bastante viável, melhorando biologicamente o solo e consequentemente física e quimicamente o solo.

\section{REFERÊNCIAS}

ANDERSON, T.H. \& DOMSCH, K.H. The metabolic quotient for $\mathrm{CO} 2$ (qCO2) as a specific activity parameter to assess the effects of environmental conditions, such as $\mathrm{pH}$, on the microbial biomass of forest soils. Soil Biology and Biochemistry, v.25, p.393-395, 1993. Disponível em: <https://doi.org/10.1016/0038-0717(93)90140-7>. doi: 10.1016/0038-0717(93)90140-7

ANDRADE, L. C.; ANDREAZZA, R.; CAMARGO, F. A. O. Atividade microbiana em solos sob doses de lodo de estação de tratamento de efluentes de um aterro industrial. Ciência Rural, v.46, n. 2, 2016. Disponível em: 
BERTICELLI, R.; DECESARO, A.; MAGRO, F.; COLLA, L. M. Compostagem como alternativa de biorremediação de áreas contaminadas. Revista CIATEC - UPF, v.8 (1), p. 12-28, 2016. Disponível em: < http://dx.doi.org/10.5335/ciatec.v1i8.4143 >. doi: $10.5335 /$ ciatec.v1i8.4143

BOHM, G.B.; BETEMPS, G.R.; BIERHALS, L.N.; FILHO, P.J. S; SCHWANZ, S.M. Uso de lodo de estação de tratamento de esgoto no cultivo de soja em Argissolo. Revista Thema, v. $11 \quad(01), \quad 2014 . \quad$ Disponível em: <http://dx.doi.org/10.15536/thema.11.2014.12-23.202>. doi: 10.15536/thema.11.2014.12-23.202

BOHM, G. M. B.; FERREIRA, R. V.; BOHM, E. M.; SANCHES FILHO, J. P.; SANTOS, D. I. R. Análise de metais traço em lodos industrial e doméstico. Revista Ibero-Americana de Ciências Ambientais, v. 10, n. 1, 2019. Disponível em: <https://doi.org/10.6008/CBPC2179-6858.2019.001.0003>. doi: 10.6008/CBPC21796858.2019.001.0003

BONINI, C. S. B.; ALVES, M. C.; MONTANARI, R. Lodo de esgoto e adubação mineral na recuperação de atributos químicos de solo degradado. Revista brasileira de engenharia agrícola ambiental, v.19, n. 4, Campina Grande, abr. 2015. Disponível em: <http://dx.doi.org/10.1590/1807-1929/agriambi.v19n4p388-393>. doi: 10.1590/1807-1929/agriambi.v19n4p388-393

BUENO, P. A. A.; OlIVEIRA, V. M. T.; GUALDI, B. L.; SILVEIRA, P. H. N.; PEREIRA, R. G.; et al. Indicadores microbiológicos de qualidade do solo em recuperação de um sistema agroflorestal. Acta Brasiliensis, v. 2, p. 40-44, 2018. Disponível em: <http://dx.doi.org/10.22571/2526-433896>. doi: 10.22571/2526433896

CARDOSO, E. J. B. N.; FORTES NETO, P. Aplicabilidade do biossólido em plantações florestais: alterações microbianas no solo. In: BETTIOL, W.; CAMARGO, O. A. (Org.) Impacto ambiental do uso agrícola do lodo de esgoto. Jaguariúna: Embrapa Meio Ambiente, p. 197-202.2000.

DE-POLLI, H.; GUERRA, J.G.M. Determinação do carbono da biomassa microbiana do solo: Método da fumigação-extração. Seropédica: EmbrapaCNPAB, 1997. 10 p. (Embrapa-CNPAB. Documentos, 37).

EMBRAPA. Centro Nacional de Pesquisa de Solos (Rio de Janeiro,RJ). Manual de métodos de análise de solo / Centro Nacional de Pesquisa de Solos. 2. ed. rev. atual. Rio de Janeiro, 1997. 212p.: il. (EMBRAPA-CNPS. Documentos; 1).

FERREIRA, E. P. B.; STONE, L. F.; MARTIN-DIDONET C. C. G. População e atividade microbiana do solo em sistema agroecológico de produção. Revista Ciência Agronômica, v. 48, n. 1, p. 22-31.2017. Disponível em: 
$<$ http://dx.doi.org/10.5935/1806-6690.20170003>.

doi:

$10.5935 / 1806-$

6690.20170003 .

GOMES, J.M. SAEG: sistema de análises estatísticas e genéticas. Versão 5.0. Viçosa: UFV, 1992. p.100.

GUIMARÃES, N. F.; GALLO, A. S.; FONTANETTI, A.; MENEGHIN, S. P.; SOUZA, M. D. B.; KÁTIA P. G. M.; SILVA, R. F. Biomassa e atividade microbiana do solo em diferentes sistemas de cultivo do cafeeiro. Revista de Ciências Agrárias, v. 40(1), p. 34-44, 2017. Disponível em: <http://dx.doi.org/10.19084/RCA16041>. doi: $10.19084 /$ RCA16041

JENKINSON, D.S. \& POWLSON, D.S. The effects of biocidal treatments on metabolism in soil. I. Fumigation with chloroform. Soil Biology and Biochemistry, vol. 8, p.167-177, 1976. Disponível em: <https://doi.org/10.1016/00380717(76)90001-8>. doi: 10.1016/0038-0717(76)90001-8

MELLONI, R.; COSTA, N. R.; MELLONI, E. G. P.; LEMES, M. C. S.; ALVARENGA, M. I. N.; NUNES NETO, J. Sistemas agroflorestais cafeeiro-araucária e seu efeito na microbiota do solo e seus processos. Ciência Florestal, Santa Maria, v. 28, n. 2, p. 784-795, abr.- jun., $2018 . \quad$ Disponível em: <http://dx.doi.org/10.5902/1980509832392>. doi: 10.5902/1980509832392

MOREIRA, S. F.; SANTOS, S. D. O.; SARDINHA, A. S.; PEREIRA JÚNIOR, A. O lodo de ETE como alternativa para a recuperação do solo em áreas degradadas. Brazilian Applied Science Review, Curitiba, v. 3, n. 3, p. 1564-1585 mai./jun. 2019.<https:doi: 10.34115/basrv3n3-006> . doi: 10.34115/basrv3n3-006

NOVAK E.; CARVALHO L. A.; SANTIAGO E. F.; PORTILHO I. I. R. Chemical and microbiological attributes under different soil cover. Revista Cerne, v. 23, n. 1; p. 1930, 2017. Disponível em: <http://dx.doi.org/10.1590/01047760201723012228>. doi:10.1590/01047760201723012228.

PEREIRA, A. C. A.; GARCIA, M. L. Efeitos da disposição de lodo de estações de tratamento de efluentes (ETE) de indústria alimentícia no solo: estudo de caso. Engenharia Sanitária e Ambiental, v.22, n.3, maio/jun, p. 531-538, 2017. Disponível em: < http://dx.doi.org/10.1590/S1413-41522016152945>. doi: 10.1590/S1413-41522016152945.

SANTOS, A. P. A.; BATISTA, S. B. Isolamento e caracterização fenotípica de microorganismos isolados de solo poluído por resíduos sólidos do bairro carrapicho município de várzea grande - mato grosso. Revista eletrônica da univag, n.12, 2015. Disponível em: <http://dx.doi.org/10.18312\%2F1980-7341.n12.2015.198>. doi: $10.18312 \% 2 F 1980-7341$.

SILVA, M. C. A.; MONTEGGIA, L. O.; CATANEO, I. Avaliação da Qualidade Microbiológica de Efluentes Sanitários Tratados por Sistemas de Lodos Ativados. Revista Caderno Pedagógico, Lajeado, v. 14, n. 1, 2017. Disponível em: 
<https://dx.doi.org/10.22410/issn.1983-0882.v14i1a2017.1499>.

doi:

10.22410/issn.1983-0882.v14i1a2017.1499

VANCE, E.D.; BROOKES, P.C. \& JENKINSON, D.S. An extraction method for measuring soil microbial biomass C. Soil Biology and Biochemistry, v. 19, p.703707, 1987. Disponível em: <https://doi.org/10.1016/0038-0717(87)90052-6>. doi: 10.1016/0038-0717(87)90052-6 